\title{
Adaptive Learning by Using SCOs Metadata
}

\author{
Danijela Milošević and Mirjana Brković \\ University of Kragujevac Technical Faculty Cacak, Cacak, Serbia
}

danijela@tfc.kg.ac.yu mira@tfc.kg.ac.yu

\author{
Matjaž Debevc \\ University of Maribor Faculty of \\ Elect. Engr. \& Comp. Science, \\ Maribor, Slovenia
}

matjaz.debevc@uni-mb.si

\author{
Radojka Krneta \\ University of Kragujevac \\ Technical Faculty Cacak, \\ Cacak, Serbia
}

radojka@tfc.kg.ac.yu

\begin{abstract}
This paper presents an adaptation scenario for tailoring instructional content towards individual learner characteristics taking into consideration his/her learning style type and subject matter motivation level. Learning resources are organized through shareable content objects (SCOs) - a small digital chunks of knowledge, independent and self described pieces of instructional material delivered via Learning Management System (LMS). We use an ontology based student model for storing student information. The scenario of designing lesson content is presented as a cross section of learning style and motivation level, based on the learning object's educational metadata. Adaptation is made through discovering those SCO's whose educational category metadata implies that SCO is to be delivered for the learning style of user. Our future work will be to provide experiment and to test our proposed guidelines in order to get feedback on how learners see the adaptive learning environments tailored to their individual learning style and motivation characteristics.
\end{abstract}

Keywords: adaptive learning environments, learning objects, learner models, learning styles, SCORM.

\section{Introduction}

Adaptive learning environments are a hot topic in the latest research and a lot of research has been done in covering different aspect of adaptivity. Also, combining reusable learning objects with adaptation scenario brings faster creating of e-learning courses and greater possibility to tai-

Material published as part of this publication, either on-line or in print, is copyrighted by the Informing Science Institute. Permission to make digital or paper copy of part or all of these works for personal or classroom use is granted without fee provided that the copies are not made or distributed for profit or commercial advantage AND that copies 1) bear this notice in full and 2) give the full citation on the first page. It is permissible to abstract these works so long as credit is given. To copy in all other cases or to republish or to post on a server or to redistribute to lists requires specific permission and payment of a fee. Contact Publisher@InformingScience.org to request redistribution permission. lor the teaching process to individual student needs.

In order to make adaptable educational hypermedia system, which is not made from scratch, a step toward reusability of adaptation features is made. Our aim was not to create adaptation rules for one usage, but to create reusable adaptation strategy which could fit to any do- 
main knowledge and will be based on higher semantic level.

Our approach tend to pursue adaptation according to generated user profile and its features which are relevant to the adaptation, e. g. the user's preferences, knowledge, goals, navigation history and possibly other relevant aspects that are used to provide personalized adaptations.

Cohen and Nycz (2006) stated that to understand e-learning, we need to understand the psychological needs of the learner. Stated in different words, the best ways to teach require involving the student in the problem to be solved. For this reason, the role of the teacher under e-learning is evolving.

We discuss here about designing lesson content tailored to individual users, taking into consideration specific learning style (Kolb learning style) and subject matter learning motivation and how could learning objects metadata be used for learning object retrieval according to the specific needs of the individual learner. Analyzing coordination between student's learning style and his motivation for specific teaching material we give guidelines for preparing learning materials according to different learner's characteristics. Those guidelines are based on pedagogical strategy and motivation factor with a strong psychological background.

Recently, few attempts have been made to model user cognitive and affective attributes in order to achieve system's adaptivity according to the needs of individual user. And while researchers agree on the importance of adaptation towards user cognitive and affective characteristics, there is "little agreement on which features can and should be used and how to use them" (Brusilovsky \& Peylo, 2001).

An approach of accommodating different learners preferences in designing instructions (Hong \& Kinshuk, 2004) is based on mechanism for matching content to individual learning style based on Felder-Silverman learning style theory. They designed a prototype for learning PHP programming with course content that matches their own learning style and the evaluation of the proposed model is going to be conducted.

Rumetshofer \& Wöß (2003) advanced a method for adapting e-learning systems to psychological factors has been presented. The method proposes extending Learning Object Metadata specification provided as IEEE standard, with psychological aspects such as Cognitive style, Learning strategy, Learning Modality and Skills. They show an adaptation framework of how all the illustrated concepts might work together to fulfill the request for individualized e-learning systems.

For presenting web-based content, learning objects are expected to be of a great use in such way that they can be easily searched for, located, shared and reused in other context. It means that content must be reusable, interoperable, accessible and durable, regardless of content delivery and management system used. In order to achieve these abilities, "learning objects" approach is a leading candidate as a choice in the next generation of instructional design, development, and delivery. The "object-oriented" paradigm was applied to learning content: a Web-based course is thought of as a collection of "learning objects" that could be shared between courses, described with its metadata, easily searched, located and reused and stored in some learning object repositories. Mustaro and Silveira (2006) stated that a repository of learning objects which has a welldefined metadata structure can be used to customize learning processes.

Learning object metadata are used for deeply describing a specific learning object in order to enable its efficient usage during retrieving and organizing in some web-based course. For presenting web-based content we relayed on SCORM (Sharable Content Object Reference Model) developed by Advanced Distributed Learning Initiative (Advanced Distributed Learning, 2004). SCORM references IMS Learning Resource Meta-data Specification and IEEE LOM (Learning Object Meta-data) as well as other specifications and further integrates these specifications with one another to form a more complete and easier to implement model. The IEEE LOM, a standard 
that is central to learning objects and repositories, was originally developed in response to the very practical needs of those assembling online collections of reusable learning materials that required standardized metadata for the purposes of discovery, management and resource sharing within and between collections (Frisen, 2005).

The smallest instructional unit is SCO (Sharable Content Object) representing single learning resource such as a unit, a lesson or a module of a course. SCO consist of assets or of a set of other SCOs. SCOs and assets are described by metadata for better searching; identification and reuse, which when used consistently increase the efficacy of belonging LMS. SCORM also provides a RTE (Run-Time Environment) that offers a standardized way for SCOs (Sharable Content Object) to communicate with LMS through the use of common API (Application Program Interface).

We elaborated an adaptation scenario for matching content to individual learning style and motivation factor, by using available learning object educational metadata. The smallest instructional unit used is SCO, and a course is composed of the other SCO sequence.

\section{Planning and Preparation of the E-learning Structure}

Planning is an important step into the e-learning development. This will ensure that the teacher remains focused not only on the immediate learning outcomes, but also in a way in were he progressively contributes and relates to the medium and long-term learning objectives. The whole process of writing things down allows teachers to articulate the desired students learning during the lesson. Thorough planning also plays a role in minimizing potential problems. Planning leads onto preparation of the materials, resources and props that will be needed in the lesson. The process is composed of four steps:

1. definition of educational design (instructional, project, open, practical or workshop design)

2. designing of activities during e-learning

3. type of interactional definition, which supports activities (e.g. student-teacher activities)

4. defining technologies, used at e-learning and supporting activities (e.g. e-mail, chat, forum, collaborative tools, interactive, web sites)

Table 1 shows example of a nine steps model of instructional design, according to Gagne (1985).

Table 1: Example of design for model of instructional design

\begin{tabular}{|l|c|c|}
\hline \multicolumn{1}{|c|}{ Activity } & Type of interaction & Technology used \\
\hline 1. Gain attention & student - teacher & e-mail, forum \\
\hline 2. Inform learner of objective & student - content & web site \\
\hline 3. Stimulate recall of prior information & student - content & web site \\
\hline 4. Present information & student - content & web site \\
\hline 5. Provide guidance & student - teacher & e-mail, forum or chat \\
\hline 6. Elicit performance & student - content & student prepare a web site \\
\hline 7. Provide feedback & student - teacher & interactive web based polling \\
\hline 8. Assess performance & student - teacher & $\begin{array}{c}\text { On-line and/or off-line web based self as- } \\
\text { sessment questionnaires }\end{array}$ \\
\hline 9. Enhance retention and transfer & student - teacher & forum \\
\hline
\end{tabular}

Table 1 represents a simple practical example of e-learning system developed for teaching $\mathrm{Hu}-$ man-Computer Interaction according to the model of instructional design. It contains PowerPoint slides, copies of book chapters; chapters contain examples, questions with answers, forum and self-assessments system with 10 questions for each chapter. Students have to make three to four home works during the course and have three direct examinations. Each exercise is strongly con- 
nected to the content of the chapter. Additionally every week, student has to find one scientific paper related to the researched field and present it shortly in 10 text lines.

\section{Adaptation to Learning Style and Motivation}

Keefe (1979) reported that the learning style represents: “...the characteristic cognitive, affective and physiological behaviors that serve as relatively stable indicators of how learners perceive, interact with and respond to the learning environment". Tailoring instructional content to specific learner needs according to his/her learning style should result in achieving learning goals more efficiently, admiring individual strengths and preferences.

We relied on the well known Kolb's learning style model (Kolb, 1984) which defines students as having a following preference:

- concrete experience or abstract conceptualization (it's how they take information in)

- active experimentation or reflective observation (how they internalize information)

The Kolb theory uses a model with two dimensions shown on Figure 1. Two lines represent different dimensions which intersect each other and form four quadrants, denoting the four personal learning styles:

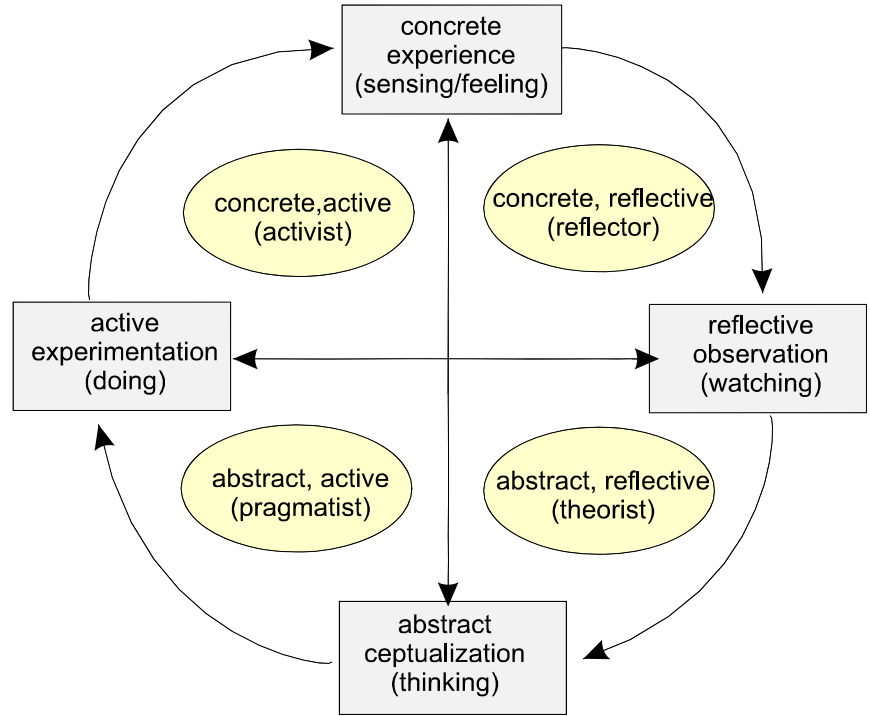

Figure 1: Kolb's learning style model

- Theorist (or Assimilator). Their characteristic question is "What?" This type of learners prefers information that is presented in an organized way and like to have time for reflection. People of this learning type can be often found in research and planning departments.

- Pragmatist (or Converger). The characteristic question for this learning type is "How?" They like to work actively on well-defined tasks and learn by trial-and-error..

- Activist (or Accommodator). The characteristic question for this learning type is "What if?" They like applying course material in new situations to solve real problems. This type of learners are often found in technical and practical fields.

- Reflector (or Diverger). The characteristic question for this learning type is "Why?" They respond well to explanations of how course materials relate to their experience, in- 
terest and future careers. This type of learners often choose to be counselors and personnel managers.

As emphasized by Felder (1996) traditional engineering instruction organize teaching process which is most suitable for Theorist learning style. If professor would concern other learning styles as well, he/she should explain the relevance of each new topic which is suitable for Reflector, present the basic information and methods associated with the topic for Theorist, provide opportunities for practice in the methods as liked by Pragmatist, and encourage exploration of applications which suites well for Activist.

Based on exploration on Kolb's learning style models we developed a table (Table 2) with the most relevant features on each learner's type. Then this table is used for our approach for instructional design for each learner's type.

Table 2. Teaching activities and learning resources types according to learning style

\begin{tabular}{|c|c|c|c|c|c|}
\hline $\begin{array}{l}\text { Teaching } \\
\text { activities }\end{array}$ & $\begin{array}{l}\text { THEORIST } \\
\text { AC/RO } \\
\text { (Assimilator) }\end{array}$ & $\begin{array}{l}\text { PRAGMATIST } \\
\text { AC/AE } \\
\text { (Converger) }\end{array}$ & $\begin{array}{l}\text { ACTIVIST } \\
\text { CE/AE } \\
\text { (Accommodator) }\end{array}$ & \multicolumn{2}{|c|}{$\begin{array}{l}\text { REFLECTOR } \\
\text { CE/RO } \\
\text { Diverger }\end{array}$} \\
\hline Theory & 1 Lecture & 0 & 0 & & lecture \\
\hline Examples & $\begin{array}{l}2 \begin{array}{l}\text { slides, theoretical } \\
\text { examples }\end{array}\end{array}$ & $\begin{array}{l}\text { applets, virtual } \\
1 \text { experiment, anima- } \\
\text { tion, simulation }\end{array}$ & 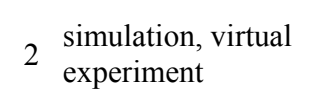 & 2 & $\begin{array}{l}\text { simulation, dem- } \\
\text { onstration }(\mathrm{A} / \mathrm{V})\end{array}$ \\
\hline Practicing & 0 & $2 \begin{array}{l}\text { self-assessment, } \\
\text { exercise }\end{array}$ & $\begin{array}{l}1 \text { solving new prob- } \\
\text { lems }\end{array}$ & 0 & \\
\hline Tests & $\begin{array}{l}\text { on line tests on } \\
\text { concepts and theo- } \\
\text { ries }\end{array}$ & $\begin{array}{l}\text { practical tasks, } \\
\text { workbook }\end{array}$ & $\begin{array}{l}\text { problem sets, skills } \\
\text { practicing }\end{array}$ & 3 & $\begin{array}{l}\text { tasks of causal } \\
\text { relations (why, if } \\
\text {...then...), multiply } \\
\text { choice questions }\end{array}$ \\
\hline \multicolumn{6}{|l|}{ Optional links } \\
\hline Index & +3 & +3 & +3 & +1 & \\
\hline Problem sets & +1 & $\begin{array}{ll}+2 & \text { practical tips from } \\
\text { expert }\end{array}$ & +2 & +3 & \\
\hline Case study & +2 & +1 & +1 & +2 & \\
\hline Group discussion & 国 & $\nabla$ & $\nabla$ & $\nabla$ & \\
\hline
\end{tabular}

Table 2 summarizes teaching activities enclosed in adaptation algorithm for adaptive content presentation and adaptive content navigation. Sequencing and navigation fit to the learning style characteristics. Learning style preference of a learner is stored in his student profile obtained after completing learning style questionnaire taken at the moment of the first learner login to the system.

Learning material should contain knowledge modules: theory, examples, practice and test, represented with appropriate learning objects. Besides, each page should provide optional links to Index, Problem sets, Case study and Group discussion ordered according to the scenario for special learning style type from Table 2 . As presented in the table, a value $(1,2,3)$ is assigned to each knowledge module stating its importance and order on the web page. Contents that have value 0 assigned to them denote that such content type should not be presented to the learner, because his learning style type doesn't prefer it or doesn't need it.

For instance, Theorist learning style type should be presented with (1) theoretical content, followed by (2) example and then (3) test. Practicing should not be presented as obligatory knowledge module for this learning type since they don't like studying trough application of knowledge. In the optional part, links should be ordered by $(+1$ - Problem sets, +2 - Case study, +3 Index) without Group discussion link, since he doesn't like team work. For each lesson module, a desirable learning resource type is shown. 
Specific learning resource type should be selected according to educational metadata resource type attached to each learning object. Learning activities are structured in the form of SCOs assigned with a learning resource type metadata value set. Depending on user's learning style preference, stored in his learner ontology LeMONT (Milošević \& Brković, 2005), sequencing of SCOs is performed by the system. The SCOs sequencing (order) is annotated in the table 1 using numbers 1 to 3 for primary learning content order $(1=$ first, $3=$ last, $0=$ hidden $),+1$ to +3 for links order and $\boldsymbol{\otimes}$ (hidden) or $\square$ (visible) for discussion link.

The level of motivation takes part in the teaching process primarily in the quantity of information presented to the student and is elaborated in detail by Milošević, Brković, \& Bjekić (2006). For example, highly motivated students tend to learn faster and to accept learning material in bigger quantities, while low motivators must be presented with smaller knowledge chunks with appropriate feedback, trying to increase their motivation.

\section{Creating Learning Objects}

Learning Objects are defined as any entity, digital or non-digital, which can be used, re-used or referenced during technology supported learning. Moreover, those who incorporate learning objects can collaborate on and benefit immediately from new versions (Wiley, 2000).

The SCO, as a learning object, contains complete instructional content and resources (files, assets) supporting the instruction. Tests are created as individual SCOs separate from the instruction. This enables SCOs of content to be used either with or without tests. Individual pieces of content are to be rearranged into a hierarchy consisting of learning objects that fall under learning objectives organized by topic. Also, SCOs can be combined into larger content structures and stored in content database.

The SCORM Content Package is the collection of all files required to run the content presented in a standard format. Content Packages enable learning content to be exchanged between developers and LMSs. All assets, SCOs, aggregation and packages require metadata in order to search for and locate content. A manifest in the form of a XML document is a description of everything contained in content package including organization and metadata. The manifest itself is also included in a content package.

As an example for fulfilling educational objective of learning to create an ASP site in Macromedia Dreamweaver, an instructional unit "ASP Site Definition" is shown on Figure 2. Activities marked with dashes are meant to be additional for learning process displayed through links. For realizing this teaching process, a SCOs for the following teaching activities need to be created: Theory, Example, Practicing, Index, Problem statement, Case study and Test. Selecting and changing different SCOs is managed by LMS with inter-SCO sequencing.

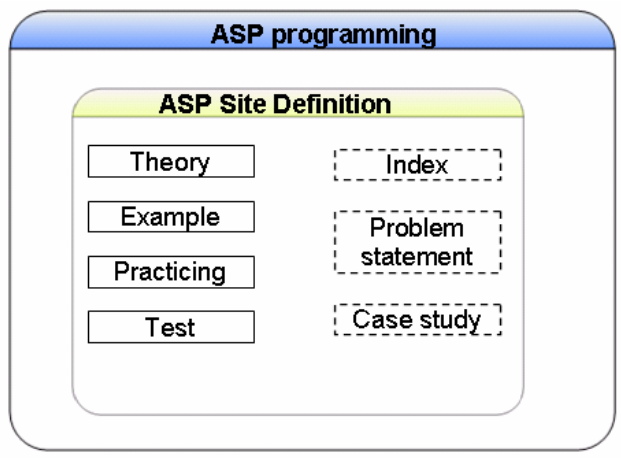

Figure 2: Learning objects identified for a lesson 
Each learning object - SCO is described with metadata. Recommended metadata fields by SCORM (Learning Systems Architecture Lab, 2003) include various metadata categories. The educational category metadata seemed the most appropriate to apply for adaptable retrieving of learning objects. The <educational $>$ element is a parent element and contains the following child elements:

-<interactivityType $>$

- $<$ learningResourceType $>$

- $<$ interactivityLevel $>$

- $<$ semanticDensity $>$

- $<$ intendedEndUserRole $>$

$-<$ context $>$

$-<$ typicalAgeRange $>$

$-<$ difficulty $>$

$-<$ typicalLearningTime $>$

- $<$ description $>$

$-<$ language $>$

The usage of available metadata is up to the content creators how and which of them will be applied. Metadata field named $<$ Learning Resource type $>$, is defined as the most dominant instructional strategy of the resource. It uses IEEE LOM 1.0 recommended vocabulary of values: exercise $\bullet$ simulation $\bullet$ questionnaire $\bullet$ diagram $\bullet$ figure $\cdot$ graph $\bullet$ index $\bullet$ slide $\bullet$ table $\bullet$ narrative text $\bullet$ exam $\bullet$ experiment $\bullet$ problem statement $\bullet$ self assessment $\bullet$ lecture, and is highly applicable for describing SCOs in our example.

A new generation of tools like metadata editors, content aggregation, sequencing and packaging editors; question and assessment editors, etc. are developed that imply learning technology standards and specifications. We used RELOAD Editor - a Content Package and Metadata Editor for creating, importing, editing, and exporting Content Packages.

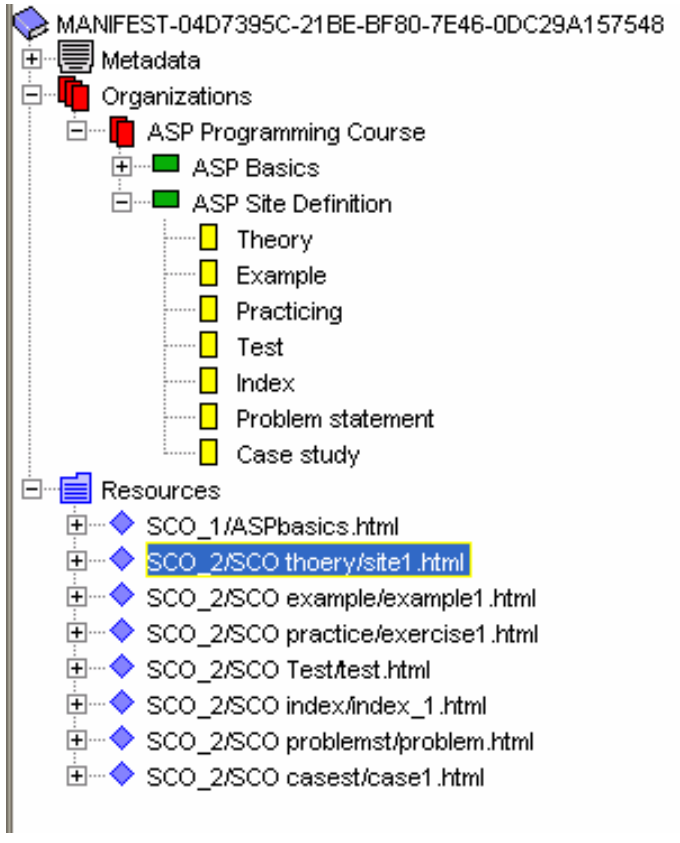

Figure 3: SCORM package in RELOAD editor

Figure 3 shows ASP programming course package with teaching activities - items and sub items that reference to SCO resources. 


\section{Adaptation Scenario}

The layered architecture supporting adaptive content presentation and sequencing is presented on Figure 4. The Learner Ontology layer provide conceptual base for learner model and is elaborated in more detail by Milošević \& Brković (2005). The next layer is ontology-based learner model including all relevant explicit and implicit learner data. That information is reliable for tailoring teaching process to individual learner characteristics. The course layer consist of the most appropriate SCOs for specific learner characteristics and selected from the Learning objects repository. Individual learner gets the most appropriate SCOs sequencing according to his individual characteristics, in this case Kolb learning style and motivation factor.

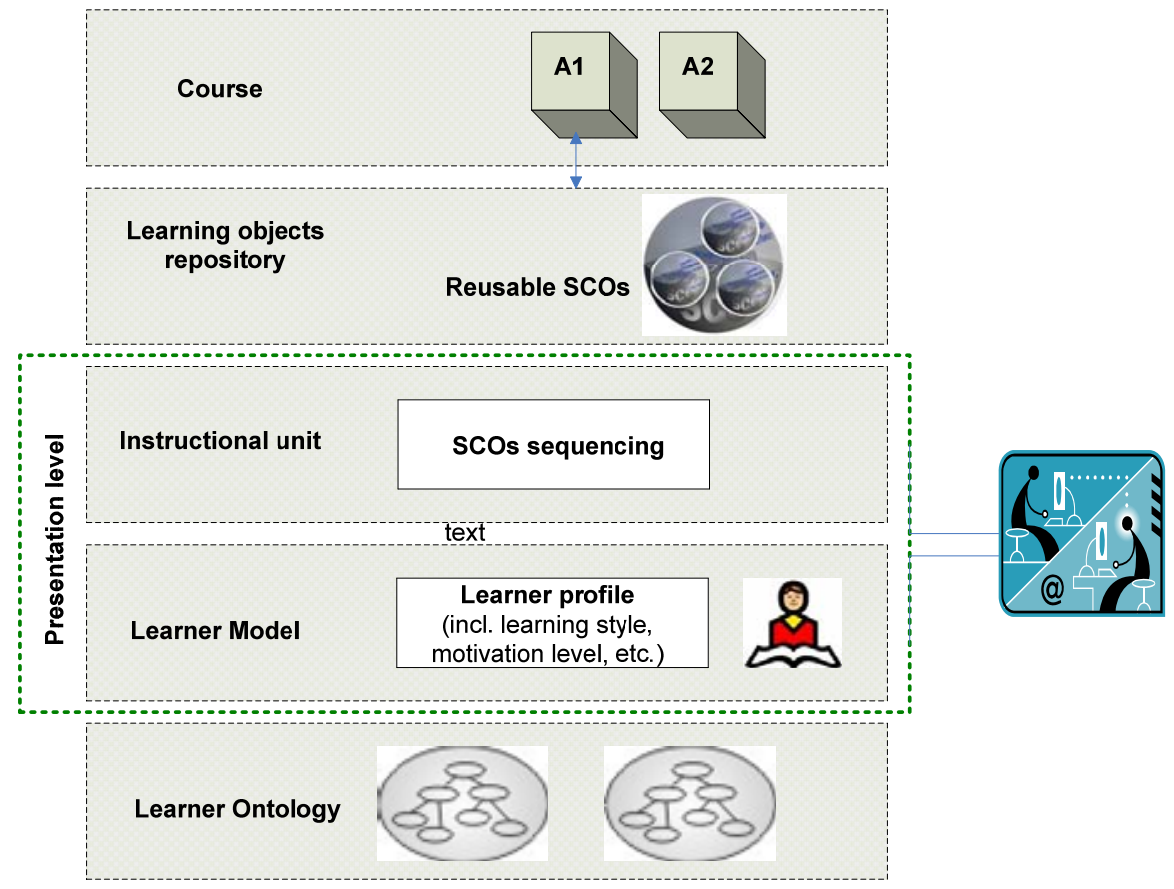

Figure 4: Architecture of adaptive teaching scenario

For each SCO specific metadata can be defined, Figure 5. For our approach we needed to define Learning Resource Type and Semantic Density metadata from educational metadata category.

According to presentation scenario from Table 2, content sequencing is generated according to order suggested for the specific learning style. As an example we showed diverger learner style'Why' learner that prefers information presented in detailed, systematic, reasoned manner, likes to use imagination to solve problems, likes working in groups, uses lectures with plenty of reflection time and prefers watching instead of doing and practicing. For each teaching activity tables suggest the order of content presentation. When choosing the instructional unit - a SCO for the learner with diverger learning style, LMS should first present a theory SCO in the form of a lecture. It means that LMS searches SCOs repository of the instructional unit using metadata searching to find the SCO whose educational learning resource type metadata has the value equal to "lecture". 


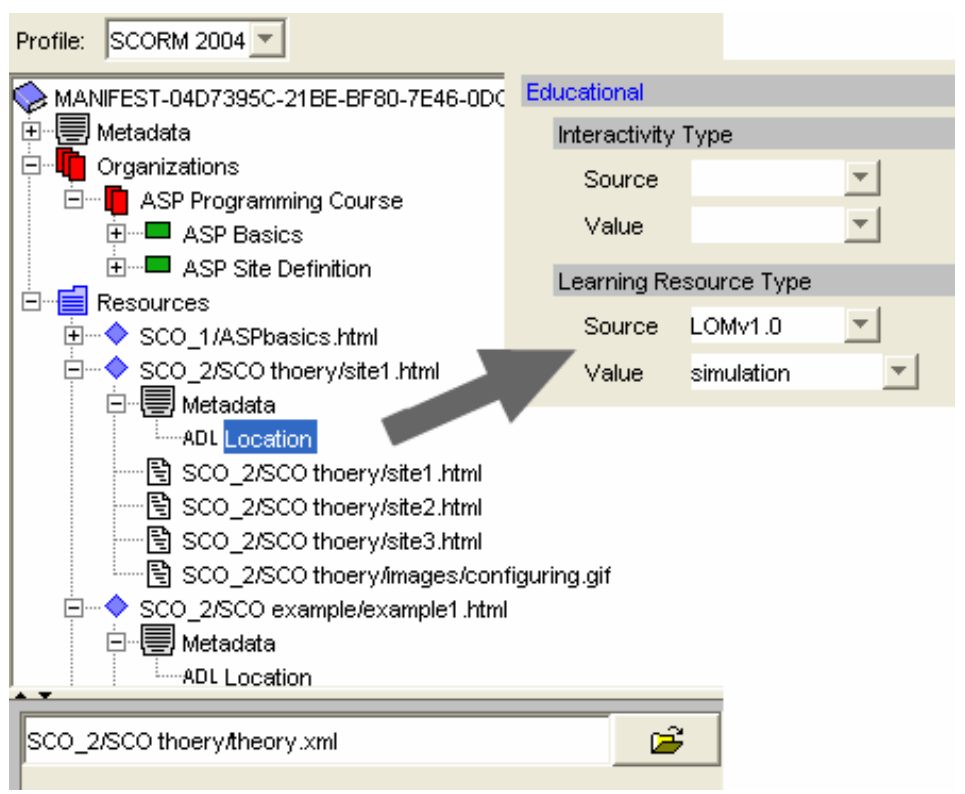

Figure 5: Metadata defined for a SCO

We chose to incorporate learning object educational metadata Semantic density (SD) denoting the complexity and semantic quantity of learning object. Stating that each SCO can have semantic density between 1 and 5 means providing low motivators with SCO that have semantic density value $<=2$, moderate motivated students with $\mathrm{SD}<=4$ in total and high motivators with learning objects with semantic density value 5 . For example, high motivated student will be presented with tree learning objects with total $\mathrm{SD}=\mathrm{SD}_{1}+\mathrm{SD}_{2}+\mathrm{SD}_{3}=1+2+2=5$, followed with test. On the contrary, low motivators will be presented step by step with three LO and each time followed with test and appropriate feedback. A possible scenario for reflector learning style is presented on Figure 6.

In the example given, mapping to diverger learning style means that the aggregation to be resented to a learner of diverger style is like one illustrated in Figure 6. Due to metadata search LMS was able to generate the above mentioned adaptive content aggregation. Metadata learning resources type field for SCOs contained in generated aggregation were: (1) lecture, (2) simulation, (3) test in the main content navigation area, and $(+1)$ index, $(+2)$, problem statement, $(+3)$ case study for SCOs of content ordered like in Figure 6. 


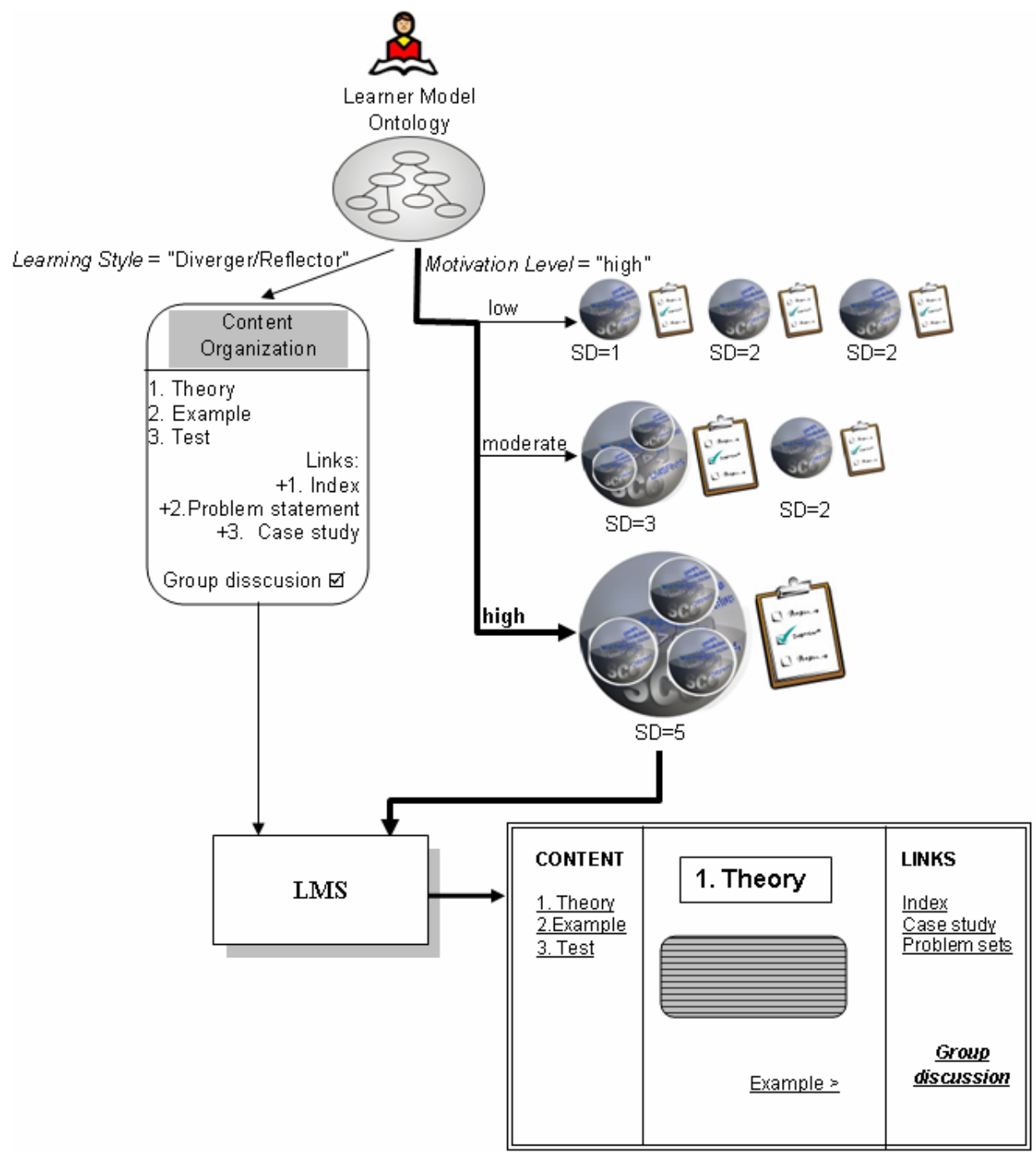

Figure 6: Adaptation scenario for Reflector learning style

\section{Conclusion}

In order to provide adaptivity of teaching process according to the individual learner characteristics and preferences maintained in learner model ontology, we used learning object metadata. The adaptation algorithm for e-learning environment is based on SCORM reference model. By applying Learning Resource Type and Semantic Density learning object metadata we enabled matching right learning objects to individual student learning style and subject matter motivation level. This way, content creators can create adaptive, accessible, shareable and reusable learning objects in a way that hide technology and standards behind the process. This scenario of adaptation is being used as framework for developing a LMS that adapts to learner's learning style preference maintained in learner model ontology. The next step would be to test the SCORM compliant elearning environment in university level education and examine the efficacy of matching content to learners concerning these individual characteristics. 


\section{References}

Advanced Distributed Learning: SCORM. (2004). Available at http://www.adlnet.org

Brusilovsky, P., \& Peylo, C. (2001). Adaptive hypermedia. User Modeling and User-Adapted Interaction, $11,87-110$.

Cohen, E. B. \& Nycz, M. (2006) Learning Objects and E-Learning: an Informing Science Perspective. Interdisciplinary Journal of Knowledge and Learning Objects, 2, 23-34. Available at: http://ijklo.org/Volume2/v2p023-034Cohen32.pdf

Felder, R. (1996). Matters of style. ASEE Prism, 6(4), 18-23.

Friesen, N. (2005). Interoperability and Learning Objects: An Overview of E-Learning Standardization, Interdisciplinary Journal of Knowledge and Learning Objects, 1, 23-31. Available at http://ijklo.org/Volume1/v1p023-031Friesen.pdf

Gagne, R. M. (1985). The conditions of learning and the theory of instruction (4th ed.). New York: Holt, Rinehart, and Winston.

Hong H. \& Kinshuk. (2004). Adaptation to student learning styles in web based educational systems. In L. Cantoni \& C. McLoughlin (Eds.), Proceedings of ED-MEDIA 2004 - World Conference on Educational Multimedia, Hypermedia \& Telecommunications (June 21-26,2004, Lugano, Switzerland), USA: AACE, 491-496 (ISBN 1-880094-53-3)

Keefe, J. (Ed.). (1979). Student learning styles: Diagnosing and describing programs. Reston VA: National Secondary School Principals.

Kolb, D. (1984). Experiential learning: Experience as the source of learning and development. Jersey: Prentice Hall.

Learning Systems Architecture Lab. (2003). SCORM. Best practices guide for content developers $\left(1^{\text {st }}\right.$ ed.). Carnegie Mellon. Retrieved from http://www.lsal.cmu.edu/lsal/expertise/projects/developersguide/developersguide/guide-v1p120050405.pdf

Milošević, D. \& Brković, M. (2005): Learner model ontology in adaptive web based educational systems, Proceedings of The 8th International Conference on Interactive Computer aided Learning - ICL2005, CD edition (ISBN 3-89958-136-9), Villach/Austria: Kassel University Press.

Milošević, D., Brković, M. \& Bjekić, D., (2006). Designing lesson content in adaptive learning environments. International Journal of Emerging Technologies in Learning - iJET, 1(2). Available at http://www.online-journals.org/index.php/i-jet/article/view/33/19

Mustaro, P. N. \& Silveira, I. F. (2006). Learning objects: Adaptive retrieval through learning styles. Interdisciplinary Journal of Knowledge and Learning Objects, 2, 35-46. Available at http://ijklo.org/Volume2/v2p035-046Mustaro.pdf

Rumetshofer, H., \& Wöß, W. (2003). XML-based adaptation framework for psychological-driven elearning systems. Educational Technology \& Society, 6(4), 18-29, Available at: http://ifets.ieee.org/periodical/6 3/4.pdf

Wiley, D. A. (2000). Learning object design and sequencing theory. Doctoral dissertation. Retrieved 03/15/2006 from http://wiley.ed.usu.edu/docs/dissertation.pdf 


\section{Biographies}
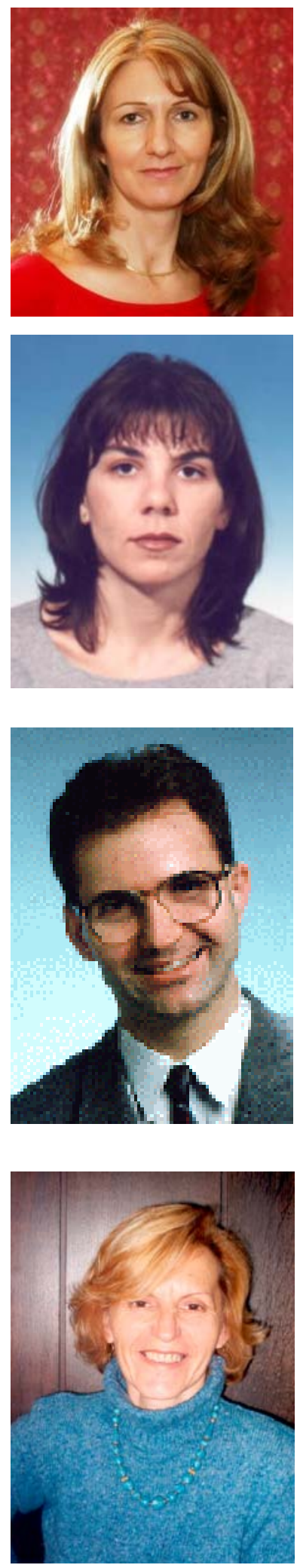

Danijela Milosevic is currently a lecturer at Department of Information technology, Technical faculty Cacak, University of Kragujevac, Serbia. She is interested in the area of applying artificial intelligence in education. Her research interests include Intelligent systems, Ontologies, Semantic Web, Student modeling and Web technologies.

Mirjana Brkovic is an Assistant trainee at Information Technology Department of University of Kragujevac Technical faculty Cacak. Her research is dedicated to standardization and adaptation of e-learning.

Matjaž Debevc received his $\mathrm{PhD}$ in technical sciences from the University of Maribor, Slovenia in 1995. Currently he is an associate professor at the Faculty of Electrical engineering and computer sciences at the same university. Since 1999 till 2003 he has been the head of the Centre for Distance Education Development at the University of Maribor. His professional interests include humancomputer interaction, user interface design, adaptive user interfaces, internet applications, cable TV, distance education and technologies for disabled. Dr. Debevc has received an UNESCO award for his work in human-computer interaction.

Professor Radojka Krneta lectures Computer Technology, Signals and Systems, Digital Control Systems and Digital Network and Communications at Technical Faculty in Cacak, University of Kragujevac, Serbia. Her current research is on Signal and Systems, Digital Control Systems and Distance Learning - specializing in Web services in education. 